International Institute for Applied Systems Analysis - A-2361 Laxenburg - Austria Tel: +432236 807 • Fax: +43223671313 • E-mail: info@iiasa.ac.at • Web: www.iiasa.ac.at

INTERIM REPORT IR-97-078/November

\title{
Sex and Size in Cosexual Plants
}

Peter G.L. Klinkhamer (klinkhamer@rulsfb.LeidenUniv.nl)

Tom J. de Jong (dejong@rulsfb.LeidenUniv.nl)

Johan A.J. Metz (metz@rulsfb.LeidenUniv.nl)

Approved by

Ulf Dieckmann (dieckman@iiasa.ac.at)

Project Coordinator, Adaptive Dynamics Network

Interim Reports on work of the International Institute for Applied Systems Analysis receive only limited review. Views or opinions expressed herein do not necessarily represent those of the Institute, its National Member Organizations, or other organizations supporting the work. 


\section{IIASA STUdies In AdAPTIVE Dynamics}

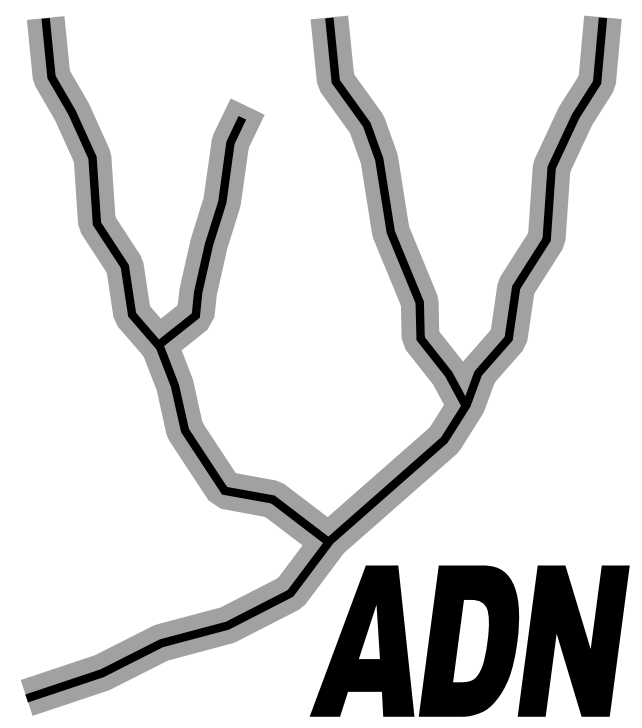

The Adaptive Dynamics Network at IIASA fosters the development of new mathematical and conceptual techniques for understanding the evolution of complex adaptive systems.

Focusing on these long-term implications of adaptive processes in systems of limited growth, the Adaptive Dynamics Network brings together scientists and institutions from around the world with IIASA acting as the central node.

Scientific progress within the network is reported in the IIASA Studies in Adaptive Dynamics series.

\section{The Adaptive Dynamics Network}

The pivotal role of evolutionary theory in life sciences derives from its capability to provide causal explanations for phenomena that are highly improbable in the physicochemical sense. Yet, until recently, many facts in biology could not be accounted for in the light of evolution. Just as physicists for a long time ignored the presence of chaos, these phenomena were basically not perceived by biologists.

Two examples illustrate this assertion. Although Darwin's publication of "The Origin of Species" sparked off the whole evolutionary revolution, oddly enough, the population genetic framework underlying the modern synthesis holds no clues to speciation events. A second illustration is the more recently appreciated issue of jump increases in biological complexity that result from the aggregation of individuals into mutualistic wholes.

These and many more problems possess a common source: the interactions of individuals are bound to change the environments these individuals live in. By closing the feedback loop in the evolutionary explanation, a new mathematical theory of the evolution of complex adaptive systems arises. It is this general theoretical option that lies at the core of the emerging field of adaptive dynamics. In consequence a major promise of adaptive dynamics studies is to elucidate the long-term effects of the interactions between ecological and evolutionary processes.

A commitment to interfacing the theory with empirical applications is necessary both for validation and for management problems. For example, empirical evidence indicates that to control pests and diseases or to achieve sustainable harvesting of renewable resources evolutionary deliberation is already crucial on the time scale of two decades.

The Adaptive Dynamics Network has as its primary objective the development of mathematical tools for the analysis of adaptive systems inside and outside the biological realm. 


\section{IIASA STUdies IN AdAPTIVE DYNAMicS}

No. 1 Metz JAJ, Geritz SAH, Meszéna G, Jacobs FJA, van Heerwaarden JS: Adaptive Dynamics: A Geometrical Study of the Consequences of Nearly Faithful Reproduction.

IIASA Working Paper WP-95-99.

van Strien SJ, Verduyn Lunel SM (eds.): Stochastic and Spatial Structures of Dynamical Systems, KNAW Verhandelingen, North Holland, Amsterdam, pp. 183-231 (1996).

No. 2 Dieckmann U, Law R:

The Dynamical Theory of Coevolution: A Derivation from Stochastic Ecological Processes.

IIASA Working Paper WP-96-01.

Journal of Mathematical Biology (1996) 34, 579-612.

No. 3 Dieckmann U, Marrow P, Law R:

Evolutionary Cycling of Predator-Prey Interactions: Population Dynamics and the Red Queen.

Journal of Theoretical Biology (1995) 176, 91-102.

No. 4 Marrow P, Dieckmann U, Law R:

Evolutionary Dynamics of Predator-Prey Systems: An Ecological

Perspective.

IIASA Working Paper WP-96-02.

Journal of Mathematical Biology (1996) 34, 556-578.

No. 5 Law R, Marrow P, Dieckmann U:

On Evolution under Asymmetric Competition.

IIASA Working Paper WP-96-03.

Evolutionary Ecology (1997) 11, 485-501.

No. 6 Metz JAJ, Mylius SD, Diekmann O:

When Does Evolution Optimise? On the Relation between Types of Density Dependence and Evolutionarily Stable Life History Parameters.

IIASA Working Paper WP-96-04.

No. 7 Ferrière R, Gatto M:

Lyapunov Exponents and the Mathematics of Invasion in Oscillatory or

Chaotic Populations.

Theoretical Population Biology (1995) 48, 126-171.

No. 8 Ferrière R, Fox GA:

Chaos and Evolution.

Trends in Ecology and Evolution (1995) 10, 480-485.

No. 9 Ferrière R, Michod RE:

The Evolution of Cooperation in Spatially Heterogeneous Populations.

IIASA Working Paper WP-96-29.

American Naturalist (1996) 147, 692-717. 
No. 10 Van Dooren TJM, Metz JAJ:

Delayed Maturation in Temporally Structured Populations with Non-

Equilibrium Dynamics.

IIASA Working Paper WP-96-70.

Journal of Evolutionary Biology (1997) in press.

No. 11 Geritz SAH, Metz JAJ, Kisdi E, Meszéna G:

The Dynamics of Adaptation and Evolutionary Branching.

IIASA Working Paper WP-96-77.

Physical Review Letters (1997) 78, 2024-2027.

No. 12 Geritz SAH, Kisdi E, Meszéna G, Metz JAJ:

Evolutionarily Singular Strategies and the Adaptive Growth and Branching of the Evolutionary Tree.

IIASA Working Paper WP-96-114.

Evolutionary Ecology (1997) in press.

No. 13 Heino M, Metz JAJ, Kaitala V:

Evolution of Mixed Maturation Strategies in Semelparous Life-Histories:

the Crucial Role of Dimensionality of Feedback Environment.

IIASA Working Paper WP-96-126.

Philosophical Transactions of the Royal Society of London Series B (1997) in press.

No. 14 Dieckmann U:

Can Adaptive Dynamics Invade?

IIASA Working Paper WP-96-152.

Trends in Ecology and Evolution (1997) 12, 128-131.

No. 15 Meszéna G, Czibula I, Geritz SAH:

Adaptive Dynamics in a Two-Patch Environment: a Simple Model for

Allopatric and Parapatric Speciation.

IIASA Interim Report IR-97-01.

Journal of Biological Systems (1997) in press.

No. 16 Heino M, Metz JAJ, Kaitala V:

The Enigma of Frequency-Dependent Selection.

IIASA Interim Report IR-97-61.

No. 17 Heino M:

Management of Evolving Fish Stocks.

IIASA Interim Report IR-97-62.

No. 18 Heino M:

Evolution of Mixed Reproductive Strategies in Simple Life-History Models.

IIASA Interim Report IR-97-63.

No. 19 Geritz SAH, van der Meijden E, Metz JAJ:

Evolutionary Dynamics of Seed Size and Seedling Competitive Ability.

IIASA Interim Report IR-97-71.

No. 20 Galis F, Metz JAJ:

Why are there so many Cichlid Species? On the Interplay of Speciation and Adaptive Radiation.

IIASA Interim Report IR-97-72.

Trends in Ecology and Evolution (1997) in press. 
No. 21 Boerlijst MC, Nowak MA, Sigmund K:

Equal Pay for all Prisoners. / The Logic of Contrition.

IIASA Interim Report IR-97-73.

AMS Monthly (1997) 104, 303-307.

Theoretical Biology (1997) 185, 281-294.

No. 22 Law R, Dieckmann U:

Symbiosis without Mutualism and the Merger of Lineages in Evolution.

IIASA Interim Report IR-97-74.

No. 23 Klinkhamer PGL, de Jong TJ, Metz JAJ:

Sex and Size in Cosexual Plants.

IIASA Interim Report IR-97-78.

Issues of the IIASA Studies in Adaptive Dynamics series can be obtained free of charge. Please contact:

Adaptive Dynamics Network

International Institute for Applied Systems Analysis

Schloßplatz 1

A-2361 Laxenburg

Austria

Telephone +432236 807, Telefax +432236 71313, E-Mail adn@iiasa.ac.at, Internet http://www.iiasa.ac.at/Research/ADN 


\section{Contents}

Introduction $\quad 2$

Experimental determination of sex allocation and fitness-gain curves 2

Plant size and sex allocation 2

Box 1. Direct effects of plant size on fitness returns 2

Box 2. Budget effects of plant size on fitness gains 2

Gain curves in wind- and animal-pollinated plants 2

Predictions on sex allocation $\quad 2$

Testing the predictions $\quad 2$

Prediction $1 \quad 2$

Prediction 2

Is SDS adaptive? $\quad 2$

Conclusion 2

References $\quad 2$ 


\begin{abstract}
There are conceptual and practical difficulties in measuring the exact shape of fitnessgain curves and sex allocation, and these hamper empirical testing of some of the basic predictions of sex allocation theory for plants. Nevertheless, our knowledge of the processes that shape fitness-gain curves allows us to formulate hypotheses to test predictions of sex allocation theory. One such hypothesis is that plants adjust their gender according to size. The connection between plant size and gender was generally thought to be weak. Recent data, however, suggest that size-dependent sex allocation (SDS) is a common phenomenon in hermaphrodites and other cosexual plants.
\end{abstract}




\title{
About the Authors
}

\author{
Peter G.L. Klinkhamer \\ Institute of Evolutionary and Ecological Sciences \\ University of Leiden \\ PO Box 9516 \\ 2300 RA Leiden, The Netherlands \\ Tom J. de Jong \\ Institute of Evolutionary and Ecological Sciences \\ University of Leiden \\ PO Box 9516 \\ 2300 RA Leiden, The Netherlands \\ Johan A.J. Metz \\ Institute of Evolutionary and Ecological Sciences \\ University of Leiden \\ PO Box 9516 \\ 2300 RA Leiden, The Netherlands \\ and \\ Adaptive Dynamics Network \\ International institute for Applied Systems Analysis \\ A-2361 Laxenburg, Austria
}

\section{Acknowledgments}

The authors thank Eric Charnov, who stimulated them to write this article, and Eddy van der Meijden, Paul Brakefield and Mirjam Heller for their valuable comments on earlier versions. 


\title{
Sex and Size in Cosexual Plants
}

\author{
Peter G.L. Klinkhamer \\ Tom J. de Jong \\ Johan A.J. Metz
}

\section{Introduction}

Sex allocation theory is one of the success stories of evolutionary biology. It provides a coherent body of theory that has proved particularly useful in generating hypotheses about sex ratios within populations, the evolution of selfing, and the evolution of mating systems.

Fitness-gain curves are central in most sex-allocation models ${ }^{1}$. They describe the relationship between investment in male or female reproduction and the gain in fitness (w) achieved. Usually the investment represents the proportion $(a)$ of resources allocated to the particular function. Fitness gain curves are often represented by a simple power function of the type $w=b a^{v}$, where $b$ is determined by the overall sex ratio of the population. If the exponent $v=1$, the gain curve is linear and fitness returns per unit of investment are independent of $a$. If $v>1$, the gain curve is accelerating and fitness returns per unit of investment increase with $a$. If $v<1$, the gain curve is decelerating.

The shapes of the male and female gain curves determine the evolutionary stability of mating systems. The hermaphrodite state is always evolutionarily stable if both curves show diminishing returns, and dioecy is always stable if both are accelerating ${ }^{1}$. If, for example, the male curve is linear, hermaphroditism will be stable if the female curve is saturating. Within cosexual species, the shapes of the gain curves determine sex allocation at the population level and how individuals within a population should adjust their sex allocation to size or other circumstances ${ }^{1}$.

In cosexual species, we expect a female-biased sex allocation if the exponent is smaller for the male gain curve, and a male-biased sex allocation if the exponent is smaller for the female curve. If both gain curves have the same exponent, for example both are linear, we expect sex allocation at equilibrium to be 0.5 . Although this is one of the most elementary predictions of sex allocation theory it has not often been tested for plants. This may be for two reasons: first, there is no general methodology for measuring sex allocation in plants; and second, the measurement of the exact shapes of the gain curves is full of pitfalls. 

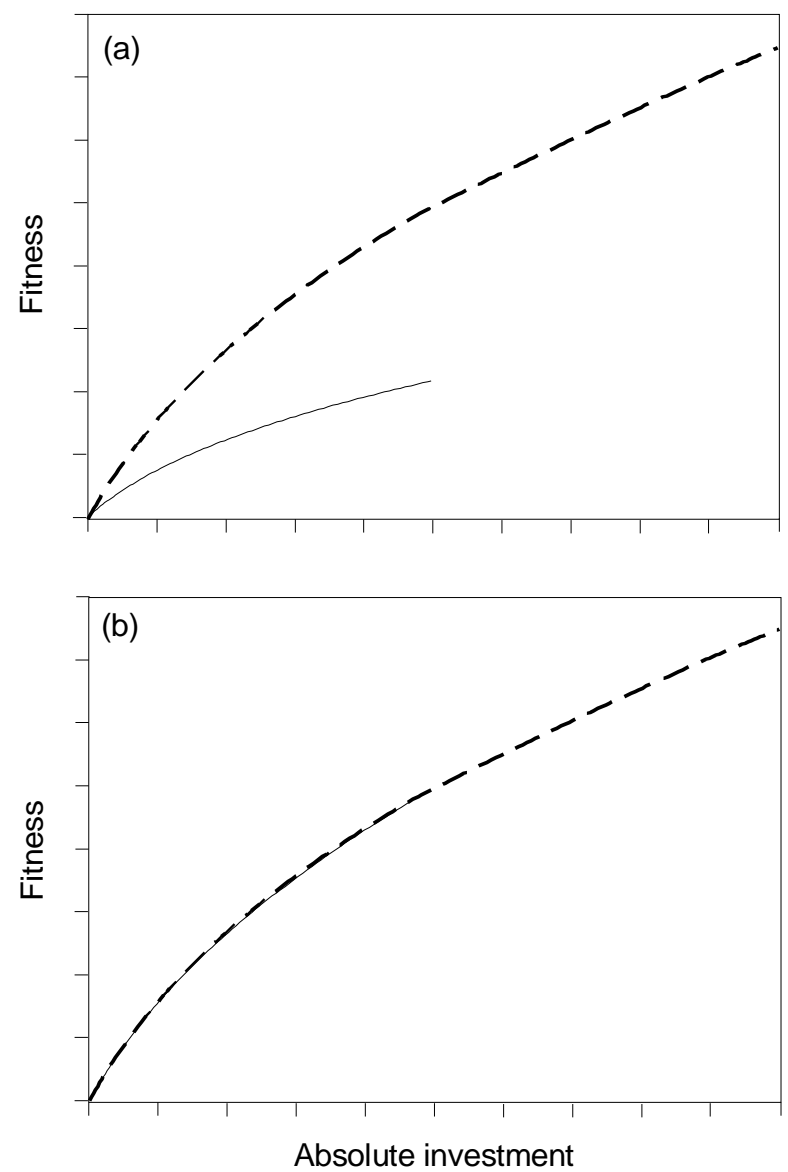

Fig. 1. Plant size may affect fitness directly or indirectly. (a) A direct effect means that, for a given investment the fitness returns differ for small plants (thin line) and large plants (thick, broken line). (b) If there is no direct effect, the fitness returns for a given absolute investment are equal for small and large plants. However, when fitness gain curves are plotted as a function of the proportion of resources invested, they are qualitatively different for small and large plants because large plants have a larger budget to invest.

\section{Experimental determination of sex allocation and fitness-gain curves}

Three major problems are encountered in the empirical measurement of sex allocation.

(1) Often it is unclear in what units we should measure the allocation - for example, in amounts of nitrogen or carbon. Ideally we should use the factor that limits investment in both functions, but experiments to determine that factor would be laborious. Furthermore, male and female function may only partly draw on the same resource pool, either because each is limited by different resources or because each uses resources at different times.

(2) We do not know how to attribute investment in the production of attractive structures, such as petals or nectar, to male and female function.

(3) If we measure allocation in units of biomass or carbon, it is not clear what proportion of the total amount in the seed is photosynthesised by the seed itself. 
These three problems can largely be circumvented by studying the trade-off between investment in male and female function, instead of looking at amounts invested directly. If, for a particular population, seed set is not limited by the level of pollination but pollen export is, we may use flowers as units to measure male allocation and seeds (or fruits) as units to measure female allocation. The trade-off between the two can be determined by comparing the flower production of plants with different seed sets, such as those resulting from controlled pollination experiments. If the numbers of flowers and seeds are denoted by $F$ and $S$ respectively, and the trade-off between $S$ and $F$ is given by a linear relationship with negative regression coefficient $r$, then producing a seed is $1 / r$ times more costly than producing a flower. In that case, the pro portion of resources invested in male function can be calculated as $F /(F+(1 / r) S)$. This provides an upper limit for any estimate of investment in male function, because the cost for flower production is attributed solely to male function.

To measure gain curves we need to establish the number of offspring produced by individuals that invest different proportions of their resources in male and female allocation. Making such a measurement presents several problems.

(1) Only since the development of molecular techniques has it been possible to assign a father and a mother to established seedlings. Many empirical studies on gain curves have used indirect measures such as pollinator visits or pollen removal to estimate male fitness. These are only partial estimates of the fitness contribution, and they may even be negatively correlated with fitness in systems where pollen discounting has an important role $\mathrm{e}^{2,3}$.

(2) For selfing organisms, we need to compare the success of the selfed progeny with that of outcross progeny. This can be problematic, especially when inbreeding effects become evident late in the life of the progeny.

(3) We need to know the fitness contributions for individuals that invest a different proportion of their resources in male and female function. If fitness returns per unit of investment are influenced by plant size, for example by plant height as might be expected in wind-pollinated organisms, we need to establish separate gain curves for individuals in different size classes. If plant size has direct effects and the absolute investments of individuals of different sizes are used to plot gain curves, these curves will appear to be non-linear even if the true gain curves are linear. If the fitness returns per unit of investment are influenced by the level of investment and not by direct effects of plant size, as might be the case in animal-pollinated plants, it is more convenient to define gain curves in terms of absolute amounts of resources invested in male function rather than the proportion invested (Fig. 1).

(4) The available genetic variation in natural populations with respect to sex allocation may be limited, so that only part of the gain curve can be determined. This problem can be solved in part by experiments in which flower and seed number are manipulated.

(5) If seeds or pollen disperse over large distances and if environmental variance is large, as it usually is in plants, the work necessary to measure the exponents of the gain curves with any statistical certainty may be excessive.

Fortunately some predictions can be tested without exact shapes for gain curves and exact values for sex allocation. In many cases, the qualitative effect of a certain factor on gain curves is sufficient to allow the formulation of hypotheses that can be 
tested with comparative methods. If the number of mates is limited, for example, selfing will lower the exponent of the male gain curve. All else being equal, theory then predicts that allocation to male function decreases with selfing rate. This prediction is supported by comparing populations and species with different selfing rates and scaling their sex allocations relative to one another ${ }^{4,5}$.

\section{Plant size and sex allocation}

Another elementary prediction of sex allocation theory is that individuals should adjust sex allocation to their size (size-dependent sex allocation, SDS) ${ }^{6-8}$. We can test this hypothesis without an exact measure of sex allocation, simply by scaling individuals within a population relative to one another.

One argument for the selective advantage of SDS focuses on gender-related mortality and applies only to perennial plants ${ }^{9,10}$. If female plants are more likely than males to die under poor conditions, then a genotype that grows in poor conditions (attaining only a small size) should emphasise male reproduction. When it encounters good conditions, the same genotype (attaining a much larger size) should emphasise female reproduction.

Another set of arguments focuses on the way in which plant size shapes the fitness-gain curves ${ }^{1,11}$. Plant size can influence fitness returns in two ways that are conceptually different and lead to qualitatively different types of SDS. First, plant size can affect fitness returns directly. For in stance, in a wind-pollinated tree, pollen from a flower on a large individual with its crown high in the canopy may be dispersed over larger distances and be more successful than pollen from a flower on a small individual in the under storey ${ }^{12}$. With such direct plant effects, fitness returns for a given absolute amount of resources invested differ for small and large plants (Fig. 1) and plants should adjust gender to their size. The most likely outcome is an abrupt shift from male to female (or vice versa) at a certain size (Box 1).

Second, if plant size has no direct effects, fitness returns for a given absolute amount of resources invested are equal for small and large plants (Fig. 1). For instance, if in an animal-pollinated species a small and a large plant produce the same number of flowers, they may gain equal male fitness. Bigger plants, However, have a larger bud get to invest in reproduction than smaller plants, so that with an equal proportion of resources invested in male or female function a large plant will produce more flowers or seeds than a small plant. Consequently, if at least one of the gain curves is non-linear if, for example, male fitness is a decelerating function of flower number - the ESS proportion of resources invested in male and female function depends on plant size. We call this the budget effect of plant size. The most likely outcome is a hermaphrodite that invests in both functions, with a gradual increase in the emphasis on male or female reproduction with plant size. The direction of the shift is determined by the ratio of the exponents of the gain curves: if the exponent for the male curve is smaller than that of the female curve, large plants are expected to emphasise female reproduction; if the exponent for the male curve is larger, the reverse is true (Box 2).

With linear gain curves, budget effects of plant size are absent but direct effects may still select for SDS. With non-linear gain curves budget effects are always present if the exponents of the gain curves are not equal, and SDS will be selected for. 


\section{Box 1. Direct effects of plant size on fitness returns}

Fitness returns per unit of investment can be directly affected by plant size. These direct effects are expressed here by a simple power function of plant size $(s)$ with exponents $c$ and $d$, respectively, in the formula for male $(m)$ and female $(f)$ fitness. When fitness gain curves are non-linear, fitness returns per unit of investment are also affected by the level of investment. This is expressed here by raising the investments in male and female reproduction to the power $u$ and $v$, respectively, in the fitness formula. If $u \neq 1$ ow $\neq 1$, small and large plants will have different average fitness returns per unit of investment because larger plants will also have a larger budget invested in reproduction. We shall call this the budget effect of plant size. Total fitness $(w)$ is found by summing male $(m)$ and female $(f)$ fitness: $w=m+f$.

$w=b_{1} s^{c}(R a)^{u}+b_{2} s^{d}(R(1-a))^{v}$, where $a$ denotes the proportion of resources allocated to male reproduction and $R$ denotes the total amount of resources allocated to reproduction; $b_{1}$ and $b_{2}$ are determined by the overall sex ratio of the population. In the ESS, each size class maximises its own fitness by choosing an appropriate value of a. Even if $b_{1}$ and $b_{2}$ are unknown, we can qualitatively study how the ESS value of a depends on $s$ and $R$.

In this box we concentrate on the direct effects of plant size on the optimal sex allocation. We assume that the male and female gain curves are linear $(u=1$ and $v=1)$ but that the slopes of the lines are different for small and large plants. Total fitness $w$ is then given by: $w=b_{1} s^{c} R a+b_{2} s^{d} R(1-a)$.

If we have a population of equally sized individuals, this leads to the well known case of linear gain curves with an ESS sex allocation of 0.5, as in (a). However, this is no longer true if we introduce size differences in the population, as in (b). Within such a population, a larger individual (solid lines) should be completely male if increasing plant size increases the slope of the male gain curve more than that of the female gain curve $(c>d)$. Similarly a small individual (dotted lines) should be completely female. If $c<d$, the reverse holds, as in (c): a larger individual should be completely female. and a smaller individual completely male.

(a)

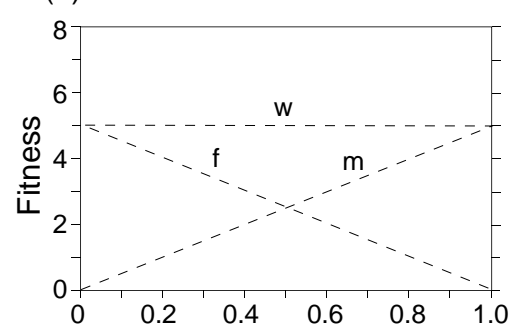

(b)

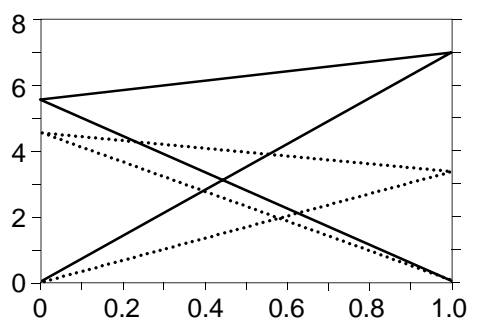

Proportion allocated to male function (c)

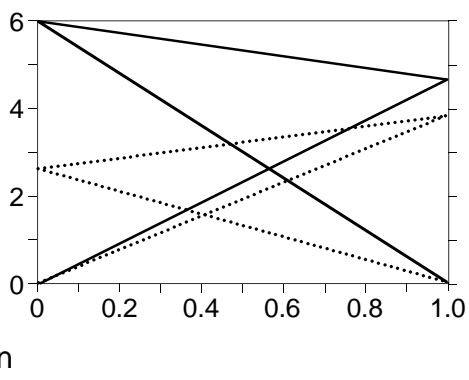




\section{Box 2. Budget effects of plant size on fitness gains}

In this box we focus on the budget effects of plant size. We assume that direct effects are absent ( $c=0$ and $d=0$, see Box 1). If small and large plants invest the same absolute amount of resources in male or female function, they have an equal fitness gain; fitness returns per unit of investment are therefore determined by the level of investment. We consider a population of individuals that invest $R$ resources in reproduction and that have an evolutionarily stable proportion, $a$, allocated to male function. Total fitness, $w$, is found by summing male fitness, $m$, and female fitness, $f: w$ $=m+f$.

$w=b_{1}(R a)^{u}+b_{2}((1-a) R)^{v}$, in which $u$ and $v$ are the exponents of the gain curves. Both gain curves are decelerating $(u<1, v<1)$, a situation that leads to stable hermaphroditism. In (a), the male curve decelerates faster than the female curve $(u<v)$; in (b), the female curve decelerates faster than the male curve $(u>v)$. Again, $b_{1}$ and $b_{2}$ are determined by the overall sex ratio of all size classes together.

The value of $a$ that maximises $w$ can be found by differentiating $w$ with respect to $a$ and setting $d w / d a$ equal to zero. $d w / d a=b_{1} u R^{u} a^{u-1}-b_{2} v R^{v}(1-a)^{(v-1)}$. Setting $d w / d a=0$ leads to:

$$
\left(b_{1} / b_{2}\right)(u / v) R^{u-v} a^{(u-1)}=(1-a)^{v-1}
$$

The left-hand side (A) and right-hand side (B) of this equality are plotted in (c) and (d). The intersection of the two lines gives the value for $a$ that maximises $w$. If $u<v$ (see c), a large investment in reproduction (solid line, corresponding to a large plant with a large budget) leads to a lower value of $a$ than does a small investment in reproduction (dotted line, corresponding to a small plant with a small budget). If $u>v$ (see d) a large investment in reproduction (solid line) leads to a higher value of $a$ than does a small investment in reproduction (dotted line). Allocation to female function should therefore increase with increasing plant size if the male gain curve decelerates more quickly, whereas maleness should increase with plant size if the female gain curve decelerates more quickly.
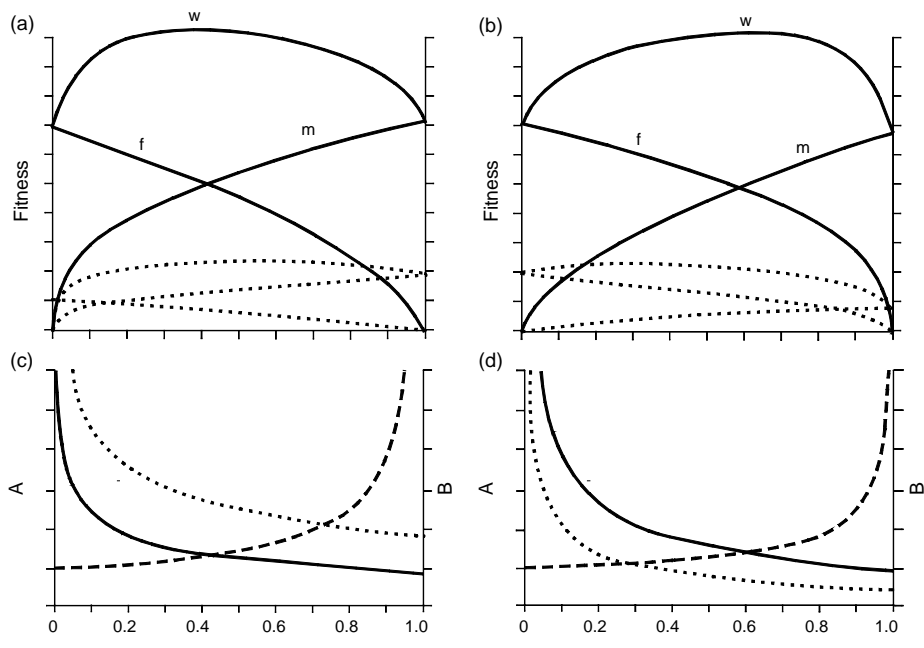

Proportion allocated to male function 


\section{Gain curves in wind- and animal-pollinated plants}

The shape of male and female gain curves has been discussed in detail by several authors ${ }^{11,13-15}$. There is agreement that both curves are likely to level off, but the principal factors in this deceleration are debated.

In animal-pollinated plants, a number of factors may cause the male fitness curve to decelerate. If a pollinator becomes saturated with pollen or if it grooms more when there is more pollen on its body, the rate of fitness gain decreases as allocation to male function increases ${ }^{16}$. Pollen can be competing for a limited number of available ovules, resulting in diminishing gains because of increased local mate competition. Recently, much attention has been given to geitonogamy (pollination by pollen from a neighbouring flower of the same plant) and the loss of pollen when a pollinator successively visits flowers on the same plant ${ }^{17-19}$. When a pollinator visits more than a single flower on the same plant pollen picked up in one flower may be lost through grooming or deposited on stigmas or other flower parts of neighbouring flowers. If the number of flowers on a plant increases, so does the length of a pollinator's visit. Plants with many flowers are therefore more likely to suffer from geitonogamy and pollen discounting. Evidence for increased geitonogamy mostly comes from the increase of selfing rates with flower number ${ }^{17}$. Direct effects of plant size on fitness returns are expected to be small in animal-pollinated plants, because pollinators will respond to their reward, that is, the number of flowers produced, rather than to the size of the plant. Processes that slow down the male gain curve in animal pollinated plants are not likely to be important in wind pollinated plants. In the latter, for example, no saturation of pollinators can occur. Also the level of pollen discounting is unlikely to depend on the number of flowers produced, that is, on the investment in male reproduction. The male gain curve in wind-pollinated plants is therefore generally thought to be more nearly linear than that in animal-pollinated plants ${ }^{1,15}$.

Direct effects of plant size are more evident for wind pollinated plants. Pollen produced at a greater height by large individuals will be dispersed further. Therefore, in wind-pollinated plants, direct effects of plant size may in crease male fitness returns in larger plants. However, depending on plant geometry, a greater proportion of the pollen produced may be caught by the plant itself in large plants and therefore not exported ${ }^{20}$. Bickel and Freeman ${ }^{20}$ suggest that the combination of these two direct effects of plant size in wind-pollinated plants leads to increased fitness returns in large plants when they have a cylindrical growth form and to reduced fitness when they have a spherical growth form.

There is no reason to assume that the mode of pollination will affect the shape of the female gain curve. Seed dispersal by wind and by animals is present in both groups. On theoretical grounds, for both animal- and wind-pollinated species, the female gain curve is expected to decelerate be cause seedlings from plants that produce many seeds suffer more from local resource competition and are therefore less successful ${ }^{11,13}$. In contrast, it has been suggested, for animal-dispersed seeds, that a greater fraction of the seeds is dispersed if the seed crop is large, but this has not been confirmed by experimental data ${ }^{14}$. 
The direct effect of plant size on the female gain curve will depend on the mode of seed dispersal. In wind-dispersed seeds especially, fitness returns may increase with plant size because seeds on large plants may be dispersed over greater distances.

The most important factors that determine the budget and direct effects of plant size are summarised in Table 1. In most published studies, most emphasis has been on the budget effects on male fitness in animal-pollinated plants and the direct effects on male fitness in wind-pollinated plants; factors affecting female fitness during and after seed dispersal have been largely neglected in plants.

Table 1. Summary of direct and budget effects on fitness gains ${ }^{\mathrm{a}}$

\begin{tabular}{|c|c|c|}
\hline & Animal pollinated & Wind pollinated \\
\hline $\begin{array}{l}\text { Direct effects } \\
\text { on male }\end{array}$ & minor $-^{b}$ & $\begin{array}{l}\text { major }+/- \\
\text { better pollen dispersal in } \\
\text { taller plants } 12 \\
\text { more pollen caught by the } \\
\text { plant itself }^{20, \mathrm{e}}\end{array}$ \\
\hline $\begin{array}{l}\text { Direct effects } \\
\text { on female }\end{array}$ & $\begin{array}{l}\text { minor/major }{ }^{c}{ }^{c} \\
\text { (better seed dispersal) }\end{array}$ & $\begin{array}{l}\text { minor/major }{ }^{c}{ }^{c} \\
\text { (better seed dispersal) }\end{array}$ \\
\hline $\begin{array}{l}\text { Budget effects } \\
\text { on male }\end{array}$ & $\begin{array}{l}\text { major }-^{\mathrm{d}} \\
\text { increased geitonogamy }^{17,19} \\
\text { increased pollen loss and } \\
\text { discounting }^{17,19} \\
\text { pollinator saturation }^{16} \\
\text { (increased LMC) }\end{array}$ & $\begin{array}{l}\text { minor - } \\
(\text { increased LMC) })^{12}\end{array}$ \\
\hline $\begin{array}{l}\text { Budget effects } \\
\text { on female }\end{array}$ & $\begin{array}{l}\text { major - } \\
\text { (increased LRC) }^{11,13}\end{array}$ & $\begin{array}{l}\text { major - } \\
\left(_{\text {increased LRC) }}{ }^{11,13}\right.\end{array}$ \\
\hline
\end{tabular}

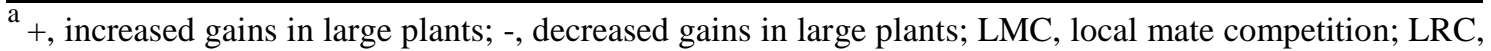
local resource competition. Factors mentioned in published studies that have not been studied empirically in great detail are shown in parentheses.

${ }^{\mathrm{b}}$ Pollinators are more likely to react to flower number than to plant size.

${ }^{c}$ Depending on mode of dispersal; major in species with wind-dispersed seeds.

${ }^{d}$ This usually produces a negative effect. However, if flower number is larger, flowers may receive more visits. This can cause a positive budget effect if pollinators are scarce.

${ }^{\mathrm{e}}$ Depending on the growth form of the plant.
} 


\section{Predictions on sex allocation}

Because of practical problems the exact shape of fitness gain curves is often not determined. In animal-pollinated plants, both male and female gain curves are expected to decelerate; without knowing their exponents, we cannot make a firm prediction about whether or not femaleness will increase with plant size. However, our knowledge of the processes that help to shape the gain curves and determine direct effects of plant size allows us to make two testable predictions on SDS.

(1) Because it is highly unlikely in a given species that direct size effects will be absent and that the male and female gain curves have the same exponent, most species should adjust their gender according to size.

(2) In wind pollinated plants the male gain curve is more linear than that in animalpollinated plants, and plant-size effects are more likely to favour pollen dispersal in large plants. Therefore, increasing maleness with plant size is expected to be more common in wind-pollinated species than it is in animal-pollinated species.

\section{Testing the predictions}

\section{Prediction 1}

In sharp contrast with the prediction that in cosexual organisms sex allocation should be size dependent, Lloyd and Bawa ${ }^{11}$ concluded, in an influential review, that in general the connection between plant size and gender expression was weak. They acknowledged, however, that at the time of their review only 'scattered piecemeal' information was available about gender expression. In addition, their data included only a single simultaneous hermaphrodite. Since Lloyd and Bawa's paper, SDS has not been put to a rigorous test. This is all the more surprising given that $72 \%$ of all plant species are hermaphrodite and that sizes of reproducing plants within a population may vary more than 100-fold. Recently, substantial data have become available and one can ask again whether hermaphrodite plants follow the predictions of sex-allocation theory or if they are invariant in their sexual behaviour.

To test if SDS is a general feature, monocarpic plants are ideal study objects because their total investment in reproduction is much more closely linked to plant size than that of perennial species. A typical example of SDS is found in hound's tongue (Cynoglossum officinale), a plant that is pollinated by bumblebees. In C. officinale, pollination is not limiting for seed set. As in all Boraginaceae, each flower may produce four seeds. The average number of seeds per flower ranges in different plants between none and 2.2. Only 5\% of all flowers produce the maximum of four seeds and about $60 \%$ of all flowers produce no seeds at all ${ }^{21}$. In C. officinale, there is a trade-off between flower and seed production: experimentally reducing seed production by preventing pollination resulted in the production of three additional flowers per reduced seed. The percentage of selfed seeds was highly variable, and increased with the number of simultaneously open flowers to $60 \%$. Flowers on small and large plants are of the same size and produce, on average, equal amounts of pollen ${ }^{22}$. Per gram of plant mass, the smallest plants in a population produced four to seven times more flowers than the largest ones, while they produced slightly fewer seeds. Consequently, gender expression in $C$. officinale is size related. Small plants emphasise male reproduction, producing 
relatively many flowers with fewer seeds per flower. Large plants emphasise female reproduction, producing relatively few flowers with more seeds per flower.

When including data from natural populations and experiments under controlled conditions, a significant SDS is found in 26 out of 44 monocarpic species (Table 2). Strikingly, 25 of these 26 species showed an increase in femaleness with plant size. Most of the studies in Table 1 were not especially designed to measure SDS and many had a rather limited range of plant sizes. If we include only the 28 studies in which plant sizes differed at least five-fold, the percentage of species with significant SDS increases from $59 \%$ to $79 \%$. In most studies, however, the number of pollen grains per flower was not included. This reduces the strength of the data set, although in the four species where pollen quantity was measured it did not alter the conclusion.

\section{Table 2. The direction of size-dependentsex allocation in monocarpic perennial species $^{\mathrm{a}}$}

\begin{tabular}{lll}
\hline $\begin{array}{l}\text { Measure of } \\
\text { sex allocation }\end{array}$ & $\begin{array}{l}\text { Increasing } \\
\text { femaleness (n) }\end{array}$ & $\begin{array}{l}\text { Increasing } \\
\text { maleness (n) }\end{array}$ \\
\hline Seeds per flower & $12(10)$ & $2(0)$ \\
Seeds per fruit & $18(12)$ & $4(0)$ \\
Fruits per flower & $7(3)$ & $1(1)$ \\
Total & $37(25)$ & $7(1)$ \\
$\frac{{ }^{a} \mathrm{n}=\text { number of species, figures in parentheses are the number of species in which the relation between }}{2}$ sex allocation and size is significant. Based on Refs. 22, 29, 40-42.
\end{tabular}

The best-studied case of SDS in perennial hermaphrodite species is that of Asclepias syriaca, where large plants strongly emphasise male reproduction ${ }^{23}$. One perennial, deceit-pollinated orchid species ${ }^{24}$ showed increased femaleness with plant size in all populations studied. In two other orchids, several populations showed increased femaleness with plant size while in some populations SDS was absent. In some perennials, small plants act solely as males, and their breeding system may mistakenly have been regarded as androdioecious (with distinct genetic male and hermaphrodite individuals) ${ }^{25}$. In three species the number of ovules per flower increased with plant mass ${ }^{26,27}$. In Discaria toumatou (see Ref. 11), and in Ranunculus species, however, gender was invariant with respect to size ${ }^{23}$. Although some species may have sex-allocation patterns that are independent of size, SDS seems a common phenomenon in monocarps and perennials. With the exception of Asclepias syriaca and Anchusa officinalis $^{29}$, all hermaphrodites observed to have SDS allocate more to female function when large.

Further evidence for SDS in perennial species comes from plants that can change sex during their life (sequential hermaphrodites). Such plants generally start off as males and change into females as they grow larger ${ }^{30}$. This sex change may be reversed under adverse conditions. Complete sex changing plants are estimated to 
comprise only $0.1 \%$ or fewer of the angiosperms but they occur in many different families. It would be of interest to know if sex change is found more often in species where direct effects of plant size are important and gain curves are linear (Box 1). Unfortunately the available data do not allow such an analysis.

\section{Prediction 2}

Data on hermaphrodite plants include only a single wind pollinated species, Vulpia fasciculata (Gramineae) ${ }^{31}$, so we shall test this prediction by looking at monoecious plants, which have separate male and female flowers on the same individual. Compared with dioecious plants, a much larger proportion of monoecious species is windpollinated. A study of monoecious species, mostly in the Asteraceae and Euphorbiaceae, showed that they usually produce more male flowers than female ones $^{32}$. This male bias is stronger in trees than in herbs. In the large tropical genus Begonia, the floral sex ratio in nearly all species is also male biased, with some species producing more than 100 times more male than female flowers (but see Ref. 33). Bickel and Freeman ${ }^{20}$ summarised data on floral-sex ratios of monoecious plants. They found that in a total of 22 species, including grasses, herbs, vines, shrubs and trees, femaleness increased with size in the eight species pollinated by animals ${ }^{20}$. In line with the prediction, eight of the 14 wind-pollinated species showed increased maleness with size. These eight species are all members of the Gramineae or Asteraceae. In addition, in the wind-pollinated, monoecious gambel oak (Quercus gambelii), tall plants that formed the oak canopy had proportionally more male inflorescences while the flowers on short plants were almost exclusively female ${ }^{34}$. In Spanish populations of the wind pollinated, androdioecious (with male and cosexual individuals) Mercurialis annua, maleness also increased with plant size in the cosexuals ${ }^{35}$.

\section{Is SDS adaptive?}

Caution is required when interpreting SDS patterns as a result of selection on gender. Several environmental conditions can cause SDS. Flowers on large plants may set more seeds because they are better pollinated. For many species, however, seed set is resource-limited rather than pollen limited (but see Ref. 36). In addition, geitonogamous pollination can reduce seed set if the species is self incompatible and the self pollen interferes with outcross pollen on the stigma. Geitonogamy may partly explain reduced seed set in large plants of Asclepias syriaca ${ }^{37}$. Lloyd and Bawa ${ }^{11}$ hypothesised that femaleness may increase with size because size itself is correlated with an improvement in the relative condition of a plant after flowering. If this hypothesis is true, we would expect the size-related gender pattern to disappear if conditions are equal for small and large plants. This was tested for Cynoglossum officinale by adding water to plants throughout the period of reproduction ${ }^{21}$ Drought is the most important stress factor in sand dunes. Plants that were watered did produce more seeds but the size-related sex allocation remained. The last explanation also fails to explain the high flower production per unit of plant mass in small plants of $C$. officinale. Apparently, plant mass affects the level of seed abortion in this species independent of environmental conditions. Smaller plants abort a higher fraction of their embryos and consequently flower production is less inhibited by developing seeds. 
Charnov ${ }^{1}$ argued that a critical test for adaptive SDS is to compare SDS of a single species in different, isolated habitats. Evolutionary theory on size-related sex allocation patterns predicts that the size effect ought to be based on relative size in the breeding population ${ }^{38}$. What is large depends on the size distribution in the whole breeding population, which may vary between habitats. In this context, Charnov ${ }^{1}$ discussed data on the sex-changer jack-in the-pulpit (Arisaema triphyllum) ${ }^{39}$. Data on size versus sex from four locations strongly suggest that if the mean size of the individuals in the population is larger, so is the size at which individuals change sex. More detailed observations of this type, on a larger number of species, are clearly needed.

\section{Conclusion}

SDS is one of the hypotheses of sex allocation theory that can be tested relatively easily. Empirical data show that SDS is a common phenomenon. For monoecious plants, data suggest that the direction of SDS is related to the mode of pollination. Future studies on SDS should concentrate on wind-pollinated hermaphrodites and on size-related pollen production. Detailed empirical studies of the processes that shape gain curves in windand animal-pollinated plants will provide a more rigorous test of whether the observed patterns of SDS are adaptive.

\section{References}

1 Charnov, E.L. (1982) The Theory of Sex Allocation, Princeton University Press

2 Wilson, P. et al. (1994) Beyond floral batemania: gender biases in selection for pollination success. Am. Nat. 143: 283-296

3 Klinkhamer, P.C.L., de Jong, T.J. \& Metz, J.A.J. (1995) Why plants can be too attractive - a discussion of measures to estimate male fitness. J. Ecol. 82: 191-194

4 Cruden, R.W. (1977) Pollen-ovule ratios: a conservative indicator of breeding systems in flowering plants. Evolution 31: 32-46

5 Charnov, E.L. (1987) On sex allocation and selfing in higher plants. Evol. Ecol. 1: 30-36

6 Charnov, E.L. \& Bull, J.J. (1977) When is sex environmentally determined. Nature 266: $828-830$

7 Charnov, E.L. \& Bull, J.J. (1985) Sex allocation in a patchy environment: a marginal value theorem. J. Theor. Biol. 115: 619-624

8 Morgan, M. (1993) Fruit to flower ratios and tradeoffs in size and number. Evol. Ecol. 7: 219-232

9 Charnov, E.L. \& Dawson, E.L. (1989) Environmental sex determination with overlapping generations. Am. Nat .134: 806-816

10 Iwasa, Y. (1991) Sex change evolution and cost of reproduction. Behav. Ecol. 2: 5668 
11 Lloyd, D.C. and Bawa, K.S. (1984) Modification of gender in seed plants in varying conditions. Evol. Biol . 17: 255-338

12 Burd, M. \& Allen, T.F.H. (1988) Sexual strategies in wind-pollinated plants. Evolution 42: 403-407

13 de Jong, T.J. \& Klinkhamer, P.C.L. (1994) Plant size and reproductive success through female and male function. J. Ecol. 82: 399-402

14 Thomson, J.D. \& Brunet, J. (1990) Hypotheses for the evolution of dioecy in seed plants. Trends Ecol. Evol. 5: 11-16

15 Charlesworth, D. \& Morgan, M.T. (1991) Allocation of resources to sex functions in flowering plants. Philos. Trans. R. Soc. London B 332: 91-102

16 Harder, L.D. \& Thomson, J.D. (1989) Evolutionary options for maximising pollen dispersal of animal-pollinated plants. Am. Nat. 133: 323-344

17 Snow, A.A. et al. (1995) The ecology of geitonogamous pollination. In: Floral Biology, Studies on Floral Evolution in Animal-Pollinated Plants (Lloyd, D.G. \& Barrett, S.C.H. eds.), pp. 191-216, Chapman \& Hall

18 De Jong, T.J., Waser, N.M. \& Klinkhamer, P.G.L. (1993) Geitonogamy: the neglected side of selfing. Trends Ecol. Evol. 8: 321-325

19 Harder, L.D. \& Barrett, S.C.H. (1995) Pollen dispersal and mating patterns in animal-pollinated plants. In: Floral Biology, Studies on Floral Evolution in AnimalPollinated Plants (Lloyd, D.G. \& Barrett, S.C.H., eds.), pp. 140-190, Chapman \& Hall

20 Bickel, A.M. \& Freeman, D.C. (1993) Effects of pollen vector and plant geometry on floral sex ratio in monoecious plants. Am. Midl. Nat. 130: 239-247

21 Klinkhamer, P.G.L. \& de Jong, T.J. (1993) Phenotypic gender in plants: effects of plant size and environment on allocation to seeds and flowers in Cynoglossum officinale. Oikos 67: 81-86

22 Klinkhamer, P.G.L. \& de Jong, T.J. Size-dependent allocation to male and female reproduction in hermaphroditic plants. In: Physiological Ecology (Grace, J. \& Bazzaz, F., eds.), Academic Press (in press)

23 Willson, M.F. \& Rathcke, B.J. (1974) Adaptive design of the floral display of Asclepias syriaca. L. Am. Midl. Nat. 92: 47-57

24 Fritz, A-L. \& Nilsson, L.A. (1995) Reproductive success and gender variation in deceit-pollinated orchids. In: Floral Biology, Studies on Floral Evolution in AnimalPollinated Plants (Lloyd, D.G. \& Barrett, S.C.H., eds.), pp. 319-338, Chapman \& Hall

25 Charlesworth, D. (1984) Androdioecy and the evolution of dioecy. Biol. J. Linn. Soc. 22: 333-346

26 Stocklin, J. \& Favre, P. (1994) Effects of plant size and morphological constraints on variation in reproductive components in two related species of Epilobium. J. Ecol. 82: 735-746 
27 Wolfe, L.M. (1983) The effect of plant size on reproductive characteristics in Erythronium americanum (Lilliaceae). Can. J. Bot. 61: 3489-3493

28 Pickering, C.M. (1994) Size-dependent reproduction in Australian alpine Ranunculus. Aust. J. Ecol. 19: 336-344

29 Andersson, S. (1988) Size dependent pollination efficiency in Anchusa officinalis (Boraginaceae): causes and consequences. Oecologia 76: 125-130

30 Freeman, D.C., Harper, K.T. \& Charnov, E.L. (1980) Sex change in plants: old and new observations and new hypothesis. Oecologia 47: 212-232

31 Watkinson, A. (1982) Factors affecting the density response of Vulpia fasciculata. J. Ecol. 70: 149-161

32 Ganeshaiah, K.N. \& Uma Shaanker, R. (1991) Floral sex ratios in monoecious species: Why are trees more male biased than herbs? Curr. Sci. 60: 319-321

33 Ågren, J. \& Schemske, D.W. (1995) Sex allocation in the monoecious herb Begonia semiovata. Evolution 49: 121-130

34 Freeman, D.C. et al. (1981) Influence of environment on the floral sex ratio of monoecious plants. Evolution 35: 194-197

35 Pannel, J.R. (1997) Variation in sex ratios and sex allocation in androdioecious Mercurialis annua. J. Ecol. 85: 57-70

36 Burd, M. (1994) Bateman's principle and plant reproduction: the role of pollen limitation in fruit and seed set. Bot. Rev. 60: 83-139

37 Pleasants, J.M. (1991) Evidence for short distance dispersal of pollinia in Asclepias syriaca. Func. Ecol. 5, 75-82

38 Blackmore, M.S. \& Charnov, E.L. (1989) Adaptive variation in environmental sex determination in a nematode. Am. Nat 134: 817-823

39 Lovett Doust, J. \& Cavers, P.B. (1982) Resource allocation and gender in the green dragon Arisaema dracontium (Araceae). Ecology 63: 797-808

40 de Jong, T.J. \& Klinkhamer, P.G.L. (1989) Size-dependency of sex-allocation in hermaphroditic, monocarpic plants. Func. Ecol. 3: 201-206

41 Dudash, M.R. (1991) Plant size effects on female and male function in hermaphroditic Sabiata angularis. Ecology 72: 1004-1012

42 Darmgaard, C. \& Loeschcke, V. (1994) Genotypic variation for reproductive characters, and the influence of pollen-ovule ratio on selfing rate in rape seed (Brassica napus). J. Evol. Biol. 7: 599-607 